\title{
On Love's Robustness
}

\section{Benjamin Ferguson ${ }^{1}$ (D)}

Accepted: 11 September 2018 / Published online: 22 September 2018

(C) The Author(s) 2018

\begin{abstract}
Recently Philip Pettit (2015) has claimed that attachment, virtue, and respect are robust goods. Robust goods require not only the actual provision of certain associated 'thin' goods, but also the modally robust provision of these thin goods across a range of counterfactual situations. I focus my attention on Pettit's account of the robust good of love, which, for Pettit, is the modally robust provision of care. I argue Pettit's account provides neither necessary nor sufficient conditions for love. In place of Pettit's account, I suggest an alternative account of love that distinguishes loving dispositions from loving actions.
\end{abstract}

Keywords Love $\cdot$ Robustness $\cdot$ Care $\cdot$ Disposition

Recently Philip Pettit (2015) has claimed that attachment, virtue, and respect are robust goods ${ }^{1}$, in the sense that they require not only the actual provision of their associated 'thin' goods, but also the modally robust provision of these goods. For example, in the case of love, Pettit claims that "in order to give me the good of love, you must provide me with [the thin good] care, not just actually, but across certain possible variations on actual circumstances" (28). Pettit's goal, he tells us, is to provide a "structurally universal conception" compatible with a wide variety of individual approaches to love that "can in principle apply everywhere" (54). In what follows I will focus my attention on the robust good of love.

Pettit's approach, which appeals to the dispositions out of which agents provide care, can be interpreted as a dispositional account of love. Dispositional accounts, as Naar (2013) points out, have many advantages. For example, they can account for idea that love is a persisting state in ways that mental event accounts (Frankfurt 1999; White 2001; Velleman 1999; Kolodny 2003) cannot. Despite these advantages, I argue that Pettit's particular dispositional account is unsuccessful. It fails to provide necessary and sufficient conditions for love. The failure of sufficiency is caused by the account's functionalist nature. The failure of necessity is caused by Pettit's conflation of love as a disposition with love as an action. In place of Pettit's approach, I suggest a quasi-dispositional alternative that accounts for the

\footnotetext{
1 'Good' is used nounally.

Benjamin Ferguson

b.r.ferguson@vu.nl
}

1 Faculty of Philosophy, VU Amsterdam, 1105 De Boelelaan, 1081, HV Amsterdam, Netherlands 
disposition of being in love-while leaving room for acts of love. In the account I propose, whether an act is an act of love depends on the reasons that motivate its performance. In this way the account overcomes objections that arise from Pettit's functionalist approach. Finally, my account remains structural in the sense that it is compatible with a wide range of positions on what constitutes a reason of love.

\section{Pettit's Account of Robust Love}

According to Pettit, the thin benefit associated with love is care, "a complex form of indulgence in which you discriminate in my favour" (12). ${ }^{2}$ A gives B the robust good of love when care is both actually and robustly provided across a suitable range of counterfactual scenarios. Pettit claims that robust provision can transform mere acts, like care, "where the dispositions out of which they are produced are irrelevant to their identity" into richer actions, like love "which essentially involve the dispositions out of which you perform them" (4). Note that Pettit focuses primarily on romantic love and for simplicity I will do the same. Both his account and the account I develop below can be extended to other forms of love.

That love is robust to changes in circumstance is a prominent platitude. Loving someone involves providing them with care and affection. And not merely contingently or on a whim. Love requires not just that we care for others in good times, but also in bad and inconvenient times. But, of course, love sometimes comes to an end. If love is robust, it is not infinitely so. What, then, are the limits of its robustness? According to Pettit, robustness is limited by three constraints: 'priming', 'support', and 'modesty'.

The priming constraint requires that you "provide me with care only in variations on the actual scenario that preserve the personal primers or prompts, the stimuli or cues, that actually move you to offer me care" (16). Priming limits the scope of love, for a particular provision of care, to a subset of possible worlds in which the primer remains present. The constraint captures the idea that love does not require us to provide care in worlds where the prompts for providing it are absent. Love might require that I comfort you over the loss of your pet, but not that I provide such comfort in worlds where the pet is alive and well.

According to the support condition, my providing you with love also does not require that I provide care in worlds where the reasons of love are outweighed by other considerations: "you should provide me with care only in variations that preserve the support that love's reasons give the provision of care: that is, in variations where love's reasons continue to outweigh the balance of competing considerations" (16). Whatever love's reasons are, they are sometimes outweighed. My loving you now does not require that I comfort you over your pet's death when this requires me to inflict serious harm on another.

Finally, love does not require that we provide care in all worlds where priming and support are both met, because as Pettit puts it, "we can easily imagine variations on actual circumstances in which, despite the satisfaction of those constraints, your disposition to provide me with care is temporarily or permanently removed or impaired. And it can hardly be a requirement on your actually giving me love that you would continue to provide the care

\footnotetext{
${ }^{2}$ Care, in Pettit's use is an external action performed for another. It is something that we "provide" (16), "give" (16), "offer" (12) or "show" (12) to others, not merely an internal or emotional state that we register in the presence of certain prompts.
} 
associated with love even if the disposition to provide it disappeared" (28). For example, the care one provides now can qualify as love, even if one would not provide a beloved care upon falling out of love. The range of worlds over which care must be provided is modest, excluding worlds where the disposition from which one acts is lost: "the idea is not that in the situation envisaged you would retain the disposition and the capacity to exercise it but fail because of contingent difficulties. The scenario imagined is a more radical one in which ... you permanently or temporarily lose the disposition" (29).

Thus, according to Pettit's full account, A provides B love iff ${ }^{3}$ A actually provides care and A provides B care in all possible worlds where priming, support, and modesty are satisfied. ${ }^{4}$

\section{Sufficiency Failure}

As we saw above, Pettit defines care as "a complex form of indulgence in which you discriminate in my favour" and love as robust care (12). Care, in Pettit's sense, is a broad term that encompasses the various acts that lovers perform for each other. This breadth makes his account more palatable; however, because care is a thin good, it is an $\mathrm{act}^{5}$ with a definition that is "independent of the disposition out of which it is performed" (3). Indeed, reasons and motives are largely absent from Pettit's account, mentioned only in the definition of the support condition. While reasons constrain the scope of robustness via the support condition, reasons characterise neither care nor robustness. This omission creates problems for the account.

First, suppose that A actually provides B care, but that A does not do so in a possible world (where priming and support are satisfied, but) in which B has a bad haircut. On Pettit's account, whether A's actual care is love therefore depends on whether the bad haircut world is modest or immodest. As we saw, Pettit claims a world is an immodest world if in it "you permanently or temporarily lose the disposition" (29). So, if A's disposition to provide care in the bad haircut world is lost, then it is an immodest world. And if it is an immodest world, then A's care in the actual world is love. ${ }^{6}$ However, if A's disposition to provide care is not lost in the bad haircut world, then, it is a modest world. If A fails to provide care in a modest counterfactual world, then in the actual world A merely provides care, not love. Thus, in order to identify whether A's care is love, we must know whether the bad haircut world is modest or not.

Note that because modesty is defined according to whether a disposition is blocked or absent, whether the bad haircut world is modest is an open empirical question that depends on whether care dispositions are lost. Some people might lose the disposition to provide

\footnotetext{
${ }^{3}$ Pettit writes, "it is necessary for you as a lover to provide me with care, not just actually, but under variations on actual circumstances that preserve suitable priming and support and satisfy modesty. Is it sufficient for giving me love that you provide the care robustly over all variations that satisfy those three constraints? ... I am happy to assume that it is" (30).

${ }^{4}$ Suppose A provides B with care under primer $\alpha$ in the actual world $\omega_{a}$. Call $P$ the set of possible worlds containing $\alpha, S$ the set of worlds satisfying support, and $M$ the set of modest worlds. According to Pettit, A's provision of care to $\mathrm{B}$ in $\omega_{a}$ is a provision of love if and only if A provides B with care for all $\omega_{i} \in P \cap S \cap M$. ${ }^{5}$ Pettit is clear that robust goods require actual action. In chapter 5 he writes, "In order to provide me with a good of attachment, virtue, or respect, so we have now seen, you must act towards me out of a corresponding disposition, discretionary or constrained. And acting towards me out of such a disposition generates the rich good as an effect" (146). I also discuss Pettit's stipulation that robust goods require action in Section 3.

${ }^{6}$ Provided A also provides care in all other worlds satisfying priming, modesty, and support.
} 
care in the presence of a bad haircut, others might not. But we cannot know a priori whether A's failure to provide care is caused by a loss of the disposition to do so, brought about by the haircut. We cannot make general claims about when care qualifies as love, instead we need to know about the fragility of $A$ 's particular disposition.

This result seems incorrect. I suspect many people believe that if A actually provides care, but does not do so in the presence of a bad haircut, then A's actual provision is not love, and they form this belief without needing to know anything about A in particular. In fact, it seems Pettit himself has this intuition. Using an example from the Importance of Being Earnest he writes,

In [the play] Jack Worthing uses the pseudonym 'Ernest' on his visits to London, as he wishes to retain a certain anonymity in the big city. Under that pseudonym he attracts the attentions of Gwendolen... and they fall in love. Or do they? Gwendolen's attachment may not earn the name of love, since it transpires that it is only as deep as Jack's pseudonym (11).

Yet, contra Pettit's conclusion, if discovering Ernest's true name destroys Gwendolen's disposition to provide care, then by his own account, her actual provision of care is, in fact, love. Whether a world is modest does not depend on why changes in circumstance affect care dispositions. It only depends on whether they affect them.

I suppose that it is possible that in some relationships, haircuts and names really are important enough to end a relationship without impugning prior care. So consider the case of a 'gold digger'. Suppose A's care for B is motivated by A's desire to inherit B's fortune. A is a skilled gold digger and avoids detection by providing care when priming and support are satisfied. However, because A's care is motivated by money, it will end if B's fortune is lost. Yet, since this change destroys A's disposition to provide care, worlds where B's fortune is lost are not worlds where love requires A to provide care because these worlds are, by Pettit's definition, immodest. Thus, on Pettit's account, the care gold diggers provide can be love. ${ }^{7}$

Now, it seems natural to think that of course modesty is supposed to target more serious cases. If you wouldn't provide care because of a bad haircut, you don't love someone. But the fact that you wouldn't provide care when someone's character changes, does not disqualify your actual care as love. But the intuitions here-and in Pettit's conclusion about Gwendolyn - are driven by normative considerations about the content of these changes in circumstance. We can see this because in all of these cases there is something that interferes with A's provision of care in a primed, supported world. But we are not, intuitively willing to accept any kind of interference as 'valid'. Intuitively, love requires care dispositions to remain intact despite certain changes in circumstance, but not others. However, capturing this difference would require a normative distinction between the kinds of things that can

\footnotetext{
${ }^{7}$ Is what gold diggers provide really care? An anonymous referee pointed out that at one point Pettit stipulates that "the generator of care... should have a certain character[;] it has to be a disposition to provide care as such" (24). In this passage it sounds as if he is excluding the act that gold diggers perform because of the disposition out of which it is produced. Yet, as I noted, elsewhere he claims that thin goods like care are mere 'acts' "where the dispositions out of which they are produced are irrelevant to their identity" (4). If we cannot appeal to the 'as such' constraint to determine what gold diggers provide, it seems that insofar as they give their target benefits similar to lovers, they provide them with care. Suppose, however, that I am wrong and gold diggers don't provide care. Even if this is the case, they are distinguished from lovers not by of modal robustness, but rather by the nature of the thin act they perform. Yet, Pettit seems to think that it is robustness that makes the difference in such cases.
} 
interfere with A's care: we want to say, e.g., that a character change 'counts', but a mere haircut does not.

Yet, to repeat, the problem for Pettit is that his modesty criterion does not include normative content. Immodesty does not depend on why the care is not performed, it only requires that its performance is frustrated by a factor's interference with or destruction of the disposition. ${ }^{8}$

Not only does Pettit's modesty condition not include normative content, it appears that he cannot add this content without frustrating the primary aim of his project. As I have shown, we cannot distinguish true lovers from gold diggers or shallow haircut enthusiasts by appealing to Pettit's priming, support and (descriptive) modesty conditions. We could distinguish these groups by adding normative content to modesty to distinguish which kinds of changes make worlds modest or immodest. But in this case, the difference between, e.g., lovers and gold diggers comes down only to the normative content in the modesty condition. And this means that robustness does no work in distinguishing mere care from love.

\section{Necessity Failure}

According to Pettit, to love another requires the actual (not merely potential) performance of an action towards them. He writes, "since 'robustly' implies 'actually' ... the fact that you robustly provide me with care means that you actually provide it" (21). And while he acknowledges it is possible "that you should be ready to show me care in the event of there being suitable prompts to do so without such an event ever arising", he insists that "you would not count as giving me love in such a case, on our ordinary conception of that good" (21-22).

Pettit's insistence here would be more plausible if it was applied only to acts of love. Indeed, it would be true by definition, for we could not perform an act of love for another without actually acting. But love, broadly construed, can be used in a different sense. When we say 'I love you' we typically refer not to an action, but to a state, such as a disposition or emotion. Unlike performing an act of love, being in love is not an action. Because being in love with another is not an action that discriminates in their favour-robustly or otherwisethe actual and robust provision of care is not necessary for love, broadly construed.

Of course, Pettit may bite the bullet here, agreeing that his is merely an account of acts of love. Nevertheless, some of the value of love seems to be associated with the disposition of being in love rather than with loving acts. It is reasonable to expect an account of the good of love to explain what is valuable about not only acts of love, but the state of being in love as well. More generally, a complete account of love should provide analyses of both, explaining what the disposition of being in love is and what kind of acts this disposition is associated with.

\footnotetext{
${ }^{8}$ Pettit does claim 'that [saying] the variations should satisfy modesty is just to say, in more familiar language, that there cannot be factors present in those scenarios that exempt you from responsibility as a lover or that excuse your failure to perform' (p. 29). This sounds initially like it might supply the missing normative content. Yet, Pettit continues that 'exemptions would apply when you lack the disposition and ... excuses when you are blocked from exercising that capacity and manifesting that disposition' (p. 29). Thus, these comments don't support a normative reading of modesty.
} 


\section{Monotonicity}

Before considering an alternative account that avoids these problems, I want to briefly illustrate an odd implication of Pettit's modesty condition. Consider again the bad haircut case. Let us suppose A actually provides B care, and that Pettit's conditions are satisfied in all other relevant worlds. Thus, whether the actual care is love depends on what happens in the bad haircut world. In that world A's disposition to provide care could be in one of three relevant states. It could be active, that is, unaffected by the haircut in the counterfactual world. It could be masked, that is present, but no act is performed. Or it could be lost, destroyed by the haircut.

\begin{tabular}{lll}
\hline A's disposition & Counterfactual care & Actual care is love \\
\hline Active & $\checkmark$ & $\checkmark$ \\
Masked & $x$ & $x$ \\
Lost & $x$ & $\checkmark$ \\
\hline
\end{tabular}

The above table summarises the effects of these dispositional states on A's counterfactual provision of care and states whether the actual care is love. The first line shows that when A's disposition is active, A provides care in the counterfactual world, and so the care in the actual world is love. The second line shows that when A's disposition is masked by the haircut, A does not provide care in the counterfactual world, so the actual provision is not love. But finally, when A's attachment to B is fickle enough for the haircut to destroy A's disposition, the counterfactual world becomes immodest. Thus, care is not required. Assuming, as we have, that care is provided in all other relevant worlds, A's actual care is love in this last case.

In combination, these three verdicts are puzzling. Surely A's attachment to B is stronger when the haircut merely masks, rather than destroys the disposition. Love should be monotonic with respect to changes to care dispositions. That is, if love is not provided when changes mask dispositions, then it is not provided when the same kinds of changes destroy them. In its current form, Pettit's conditions imply that when care disposition are more fickle, the probability that love is provided is greater. Whether this issue represents a challenge to the accounts' sufficiency or necessity depends on how one thinks it should be resolved. We could either say that because the actual care is love in the lost dispositions world, the actual care must also be love in the masked world, or we could say that because the actual care is not love in the masked world, it actual care must also not be love in the lost dispositions world.

On one hand, if we think actual care is love even if dispositions are masked in counterfactual worlds, then it represents a challenge to Pettit's claim that robust provision is necessary for love, since in such masked worlds priming, support, and modesty are satisfied, but care is not provided.

Pettit could alter his modesty condition so that modesty is not satisfied in such worlds. In this case, immodest worlds would include not only scenarios in which you permanently or temporarily lose the disposition, but also cases where a disposition is masked. However, unless he also distinguishes between various causes of masking, (e.g., by including a reference to agents' motives), this strategy makes the modesty condition superfluous. Without such a distinction, all masked worlds must be immodest worlds. To see why, consider a possible world where priming and support are satisfied, but an agent does not act. She might fail to act either because she lacks the relevant disposition, or because the 
disposition is masked. But unless actions can be prevented by ways other than dispositions being masked or absent ${ }^{9}$, all counterfactual priming and support worlds in which she does not act must be immodest worlds. There would be no possible world in which the agent fails to act and in which modesty is satisfied. Thus, the modesty condition would do no work in distinguishing care from love. Avoiding the challenge to necessity by modifying modesty is not a viable solution.

On the other hand, Pettit could retain his claim that when care is not provided in worlds where the disposition is masked, then actual care is not love. But if one accepts my claim that (under the same kinds of changes) more fickle dispositions should not imply stronger attachments, it seems we should also conclude that actual care is not love when care is not provided in counterfactual worlds where the disposition is also lost. But since Pettit's existing conditions cannot distinguish mere care (in the lost worlds) from love, we would have to conclude that they are insufficient. In order to address this insufficiency, Pettit could, again, attempt to modify modesty: in this case by narrowing the scope of immodest worlds. Once again, his functionalist account prevents him from distinguishing between various motivating reasons that might cause the masking. So, it seems he would have to claim that all worlds where the disposition is lost are modest worlds. However, if all masked and lost worlds are modest, and these exhaust the reasons an action might not be performed, then in order for actual care to be love, A must provide care in all possible worlds satisfying priming and support (or to put it the other way around, if A fails to care in any possible world satisfying priming and support, then her actual care is not love). Here too the modesty condition would be superfluous and avoiding the challenge to sufficiency by modifying modesty is also not a viable option.

\section{A Robust Alternative}

So far I have argued that Pettit's conditions are not necessary for love, broadly construed because they do not apply to the disposition of being in love. And even if his account is restricted to the domain of acts of love in order to avoid the necessity failure, the omission of agents' motivating reasons causes problems in cases like the gold digger. Such cases show that intuitions about whether a world is 'really' modest or immodest rely on tacit appeals to the kinds of changes involved and the reasons that motivate agents' care. ${ }^{10}$ Pettit's conditions are thus insufficient to distinguish loving acts from mere care. But might robustness be necessary for distinguishing acts of love from care? I will revisit this question in the final section below.

First, I will outline an alternative that has certain similarities Pettit's account, but which avoids its necessity and sufficiency problems as well as the puzzling monotonicity issue. Like Pettit's account, the account that follows is structural, in the sense that it is compatible with a wide variety of individual approaches to love. Furthermore, it is, in principle, compatible with many existing philosophical accounts of the kind of motives and attitudes involved in love since it offers a structure that distinguishes care from acts of love and acts of love from love as a disposition. It is not my intention to offer a complete account of the

\footnotetext{
${ }^{9}$ Note that while there exist other confounders, such as finks, these do not lead to the non performance of the action, but rather the performance for the wrong reason (a distinction Pettit's framework cannot accommodate).

${ }^{10}$ Appeals to motivating reasons are also required for any plausible solution to the monotonicity problem.
} 
kinds of motives proper to love or to defend the my robustness account against alternative approaches to love. ${ }^{11}$

Unlike Pettit's account, in my account robustness plays no role in distinguishing acts of love from care. And unlike Pettit's account, I draw a clear distinction between the disposition of being in love and the performance of acts of love. In this way I account for the intuitive relationship between modal robustness and love that also motivates Pettit's own approach. The account that follows is, partly a dispositional account, because it associates the nounal use of 'love' - being in love-with a disposition. But the account is not only a dispositional account because it also accommodates verbal uses of 'love'. It is, in this sense, quasi-dispositional.

Modal robustness is associated with the nounal sense of love as a dispositional attitude. This is because dispositions are best understood in counterfactual terms. According to the simple counterfactual analysis of dispositions, to say $\mathrm{A}$ is disposed to $\phi$ under conditions $\mathrm{C}$ is just to say that $\mathrm{A}$ would $\phi$ in all worlds where $\mathrm{C}$ obtains. While the general association of counterfactuals with dispositions is compelling, this simple analysis admits to many well known exceptions where finks (Lewis 1997), masks (Johnston 1992), and other complications (Manley and Wasserman 2008) prevent A from $\phi$-ing when C or cause A to $\phi$ without C. Similar problems confront Pettit's account of love as well. For example, gold diggers are finks. Although they are not in love, when the right primers are present, they mimic the behaviour of lovers.

These problems for counterfactual analyses have prompted arguments that ordinary dispositions are not exceptionless. For example, Manley and Wasserman argue A is disposed to $\phi$ when $\mathrm{C}$ if and only if A would $\phi$ in some suitable proportion of $\mathrm{C}$ worlds. ${ }^{12}$ Not only does this approach solve many problems for a general analysis of dispositions in terms of counterfactuals, it also seems especially well suited to the context of dispositional attitudes in agents. If we apply this general account of dispositions to the dispositional sense of love we may say:

1. A is in love with B iff A would $\phi$ in some suitable proportion of P worlds (worlds where a primer is present).

In the case of love, to $\phi$ is to perform an act of love. Contra Pettit, not all caring acts are potentially loving acts. Instead,

2. A performs an act of love iff A performs an act of care for the right reasons (those appropriate to love).

Love, in a broad sense, comprises both being in love, defined in (1) and acts of love, defined in (2).

First consider the definition of being in love in (1). A's $\phi$-ing in at least one P world is a necessary condition for A's being in love. This allows A to be in love with B without $\phi$-ing in the actual world and at least some other worlds when primers are present. This overcomes the aforementioned necessity failure. A can be in love with B even when A does not actually perform actions that discriminate in B's favour. Yet, the requirement that A would $\phi$ in at least one world retains a weak connection between being in love and the performance of

\footnotetext{
${ }^{11}$ See for example Nozick (1989) and Scruton (1986) for union-based accounts; Velleman (1999) and Kolodny (2003) for appraisal-based accounts; Rorty (1993) for an emotion-based account; and Frankfurt (1999) and White (2001) for concern-based accounts.

${ }^{12}$ See also Fara (2005).
} 
loving acts. Though A may love B without acting, it must at least be possible that A would have acted.

If $\phi$-ing in at least one $\mathrm{P}$ world is necessary for love, what is the threshold for sufficiency - in how many P worlds must A $\phi$ for A to be in love with B? As Manley and Wasserman write, "how big a proportion is 'suitable' will depend... on the context of utterance" (76). Pettit too acknowledges that "within a given culture, of course, there will also be room for any individuals or subgroups to customize those standards and give themselves a conception of the requirements of love that is distinct" (18). The spirit of these claims seems correct. While being in love is a disposition that requires $\phi$-ing in some $\mathrm{P}$ worlds, the sufficient proportion is a contingent matter that is contextually and culturally variable. (However, I am sceptical of Pettit's rather strong claim that individuals can influence sufficiency norms.)

Pettit's account of robustness required the provision of care in all worlds satisfying his conditions. The definition in (1) omits the universal quantifier and, by so doing, the approach also removes the need for the modesty condition, thus side-stepping the monotonicity problem. Because being in love with $\mathrm{B}$ does not require $\mathrm{A}$ to $\phi$ in all $\mathrm{P}$ worlds, there is no need to account for $\mathrm{P}$ worlds where A does not $\phi$ because A has, say, fallen out of love. Instead, A's being in love with B is stronger or weaker depending on the number of $\mathrm{P}$ worlds in which A would $\phi .^{13}$

Now consider the definition of acts of love in (2). Acts of love are actions performed for reasons proper to love. The right reasons for love will vary between conceptions, but contra Pettit, not all reasons for providing care are reasons that are compatible with love. Care on this account (as in Pettit's account) is more basic than love. It is roughly analogous to 'benefit'. Love's reasons are generally other regarding and often related to the beloved's welfare or happiness. For example, although gold diggers perform acts of care that are beneficial to the other, the reasons that motivate their actions are not those proper to love, even when their care is robustly provided. A full conception of loving acts would require an account of the reasons proper to loving acts that provides a principled distinction between these and other reasons for action.

Many such accounts exist and could be used to provide a full account. The structural, quasi-dispositional account developed here is, in principle, compatible with many motivesensitive distinctions between love and care. Indeed, some substantive approaches to love, such as emotion-based and appraisal-based accounts seem especially well suited to this task. The broader point that my account presses is that being in love is a disposition. In particular, a disposition to perform acts of love. Whatever else acts of love may be, they can be distinguished from other acts we perform by the kinds of reasons that motivate them. Substantive accounts of love say something about what these reasons may be. They may be based on emotions (Hamlyn 1989), or recognition of the other's dignity (Velleman 1999). They may be other regarding or 'we' regarding (Solomon 1988; Nozick 1989). While my quasi-dispositional account relies on accounts of these motivating reasons, it presupposes no particular account of what they consist in.

\footnotetext{
${ }^{13}$ It should be noted that Pettit acknowledges that "only the weaker requirements can be satisfied in practice, but for the sake of simplicity, I shall often speak as if the disposition you need in order to give me the good of love... determinately ensures the presence of the thin benefit in all variations on actual circumstances" (27). Yet, Pettit does not seem to realise this is more than a simplifying assumption. It alone motivates the need for the modesty condition. Dropping the assumption alters the account's verdicts in various cases.
} 


\section{Robustness Revisited}

According to the account developed here, although the reasons that distinguish acts of care from acts of love might themselves be robust, the modal robustness of these reasons is not necessary for acts of love. Pettit could accept that the care involved in love should be limited to properly motivated care, while maintaining that, in part, what it means for care to be properly motivated is that the reasons which prompt the provision of care are themselves robust. In this sense then, an appeal to robustness would still be necessary in order to distinguish loving acts from caring acts.

Yet, when we focus only on loving acts, the claim that robustness is necessary is not entirely convincing. For an act to be a loving act, robustness is not required. Loving acts must follow from the proper motives, but need not overcome possible countervailing motives in alternative scenarios. Even if circumstances in another world are such that A's motivation to perform a loving act is outweighed by a bad haircut in that world, it is surely possible that the act that is performed in the actual world, where the motives are not outweighed, is a loving act when the motives that prompt it are appropriate. Robustness is necessary for the disposition of being in love. If A's provision of care to B is motivated by the right reasons, but is very fragile to intervention, then, though her actual act may be a loving act, we will be unlikely to conclude that $\mathrm{A}$ is in love with $\mathrm{B} .{ }^{14}$

Pettit is correct to insist that love, in a broad sense, requires modal robustness. However, the robustness associated with love is not captured by Pettit's three conditions. Nor is it necessary for acts of love. Modal robustness is associated with love, broadly construed, because to be in love is to be disposed to perform acts of love (not acts of care). That is, to be in love is to be motivated to act by certain kinds of reasons in a sufficient number of possible worlds.

Acknowledgments This paper was presented at the University of St. Gallen, VU Amsterdam, the University of Amsterdam, Creighton University, and Uppsala University. I thank those present for their comments. I also thank Vuko Andrić Susanne Burri, Martin van Hees, Jens Johansson, Sebastian Köhler, Alice Obrecht, Philip Pettit, Phil Robichaud, Orri Stefansson, Chris Thompson, Jojanneke Vanderveen, Alex Voorhoeve, and Richard White for helpful suggestions.

Open Access This article is distributed under the terms of the Creative Commons Attribution 4.0 International License (http://creativecommons.org/licenses/by/4.0/), which permits unrestricted use, distribution, and reproduction in any medium, provided you give appropriate credit to the original author(s) and the source, provide a link to the Creative Commons license, and indicate if changes were made.

\section{References}

Fara M (2005) Dispositions and Habituals. Nous 39:43-82

Frankfurt H (1999) Autonomy, necessity, and love. In: Necessity, volition, and love. Cambridge University Press, Cambridge, pp 129-41

Hamlyn D (1989) The phenomena of love and hate. In: Soble A (ed) Eros, agape, and philia: readings in the philosophy of love. Paragon House, New York

\footnotetext{
${ }^{14}$ Note that the distinctions between care, loving acts, and being in love are similar to the Kantian distinctions between dutiful acts, morally worthy acts, and morally virtuous persons. Indeed, my argument against the necessity of robustness for loving acts is a paraphrase of Herman (1981) argument against the necessity of robustness for moral worth.
} 
Herman B (1981) On the value of acting from the motive of duty. Philos sRev 90(3):359-382

Johnston M (1992) How to speak of the colors. Philos Stud 68:221-63

Kolodny N (2003) Love as valuing a relationship. Philos Rev 112:135-89

Lewis D (1997) Finkish dispositions. The Philosophical Quarterly 47:143-58

Manley D, Wasserman R (2008) On linking dispositions and conditionals. Mind 117:59-84

Naar H (2013) A dispositional theory of love. Pac Philos Q 94(3):342-357

Nozick R (1989) Love's bond. In: The examined life: philosophical meditations. New York, Simon \& Schuster, pp 68-86

Pettit P (2015) The robust demands of the good. Oxford University Press, Oxford

Rorty A (1993) The historicity of psychological attitudes: love is not love which alters not when it alteration finds. In: Badhwar N (ed) Friendship: a philosophical reader. Cornell University Press, Ithaca, pp 73-88

Scruton R (1986) Sexual desire: a moral philosophy of the erotic. Free Press, New York

Solomon R (1988) About love: reinventing romance for our times. Simon \& Schuster, New York

Velleman J (1999) Love as a moral emotion. Ethics 109:338-74

White R (2001) Love's philosophy. Rowman \& Littlefield, Lanham 